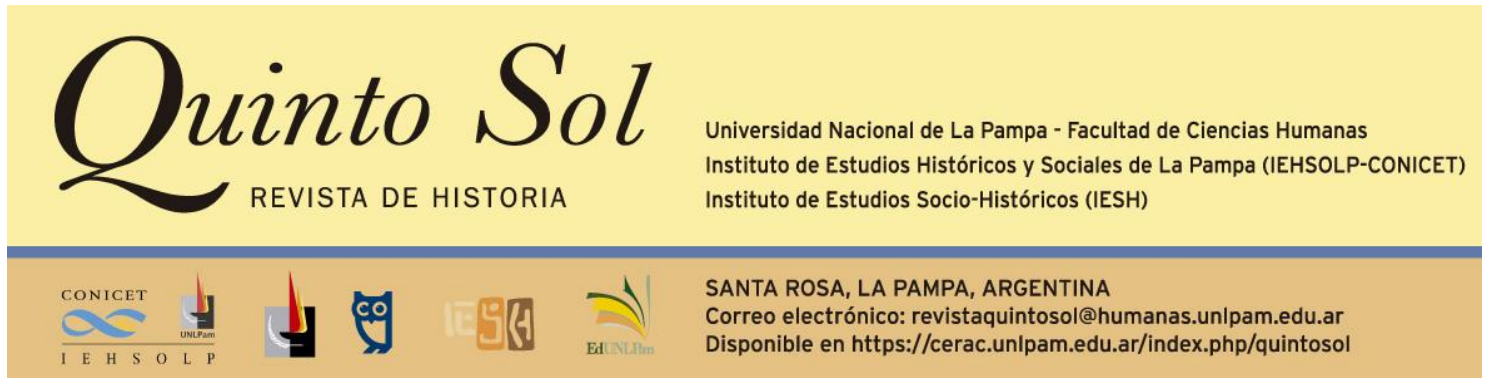

Quinto Sol, vol. 23, n 1, enero-abril 2019, ISSN 1851-2879, pp. 1-4

DOI: http://dx.doi.org/10.19137/qs.v23i1.3561

Esta obra se publica bajo licencia Creative Commons 4.0 Internacional. (Atribución-No ComercialCompartir Igual)

\title{
Flavia Fiorucci y Laura Graciela Rodríguez (Comp.) Intelectuales de la educación y el Estado: maestros, médicos y arquitectos. Buenos Aires: Universidad Nacional de Quilmes, 2018, 270 páginas.
}

\section{María de los Ángeles Lanzillotta}

Universidad Nacional de La Pampa. Facultad de Ciencias Humanas. Instituto de Estudios Históricos y Sociales de La Pampa. Instituto de Estudios Socio-Históricos

Argentina

Correo electrónico: marialanzillotta@hotmail.es

El libro reúne contribuciones que focalizan en el análisis de figuras intelectuales que aportaron a la organización de distintos espacios y reparticiones del sistema educativo en Argentina. La obra es representativa de una línea de estudios en expansión, una historia de la educación en el país, que al examinar la producción y las prácticas intelectuales de diversos actores sociales, pone en agenda un abanico de problemas nuevos originados a partir de los aportes de varias perspectivas historiográficas -como las contribuciones de la historia de la educación centrada en las prácticas escolares, las investigaciones sobre las burocracias estatales o la historia de los intelectuales-, enfoques que en los distintos capítulos evidencian reciprocidades y debates fecundos. 
Las diferentes partes de la compilación siguen el hilo conductor de los recorridos biográficos de los actores involucrados, algunos analizados "en espejo" con otras figuras intelectuales de la época. Los contrapuntos entre los agentes se conforman en función de los trayectos formativos, los posicionamientos al interior de las reparticiones estatales, las redes de sociabilidad, para poder, de ese modo, identificar las condiciones de posibilidad de las estrategias personales y los intersticios dejados por los sistemas normativos. Más allá de las disímiles intensidades en la trama explicativa de cada segmento biográfico, los estudios reunidos resaltan la correspondencia entre las prácticas profesionales y los posicionamientos intelectuales, deteniéndose en las tensiones, los dilemas y los virajes que los sujetos debieron enfrentar.

A excepción del primer capítulo que analiza la formación de figuras que precedieron a la profesionalización del campo pedagógico en la primera mitad del siglo XIX, en el resto de los trabajos la periodización está centrada en la primera mitad del siglo XX. De esta forma, el libro pone en tensión algunos consensos que atravesaron los estudios sobre la historia de la educación en Argentina. Por un lado, el capítulo inicial discute con las investigaciones que focalizaron en la Ley 1420, el normalismo y las producciones intelectuales exógenas como el andamiaje principal a partir del cual se organizó el sistema educativo. Por otro, los trabajos comprendidos en la compilación dejan sentada la presencia de distintas perspectivas entre los artífices de la gestión educativa y sus distancias con los enfoques y prácticas hegemónicas de su tiempo, al igual que hacen explícita la necesidad de indagar en la diversidad de contextos y figuras de espacios sociales y educativos locales o provinciales.

En la presentación, las compiladoras fundamentan y exponen los principales lineamientos y categorías teóricas que estructuran la obra, como los conceptos de intelectuales, productores culturales y Estado. A esta introducción le suceden siete capítulos organizados en función de dos ejes, una primera parte, de mayor extensión, se presenta bajo el título "Maestros y maestras en tiempos cambiantes" e incluye los estudios de José Bustamante Vismara, Laura Graciela Rodríguez, Flavia Fiorucci y Paula Caldo; la segunda parte, denominada "Intelectuales y expertos: médicos y arquitectos en la escuela", comprende las investigaciones de Adrián Cammarota, Karina Ramacciotti y Daniela Cattaneo.

El capítulo de José Bustamante Vismara analiza distintas intervenciones y producciones educativas de docentes que entre 1820 y 1840 -antes de la profesionalización de la pedagogía- desarrollaron actividades en las provincias de Buenos Aires, Córdoba y Entre Ríos, y dieron a conocer alguna reflexión acerca de esas tareas. El estudio explora las producciones de tres grupos de docentes, atendiendo a la formación -muchos de ellos son idóneos-, la acreditación de sus saberes y sus vinculaciones con los sectores de poder político en el marco de una diversidad regional subyacente. La investigación aporta una periodización, una caracterización de distintos perfiles docentes y de sus estrategias para intervenir en los espacios educativos provinciales y esboza la dinámica de un proceso de transición escasamente estudiado.

En el capítulo segundo, Laura Rodríguez indaga en el recorrido biográfico del inspector y funcionario Juan Francisco Jaúregui (1870-1960) y focaliza en las relaciones 
"diversas y complejas" que entabló con los distintos agentes estatales. Analiza el itinerario desde su formación, los puestos que ocupó en su trayectoria profesional y los vínculos que estableció con conservadores, radicales, católicos y socialistas; muestra la tensión entre sus nombramientos y algunos de los planteamientos intelectuales del inspector. Se nutre de sus escritos periodísticos para desarrollar el ideario de Jaúregui, enfocado en la defensa del laicismo, el panteón liberal y el nacionalismo tolerante con la inmigración, al mismo tiempo que plantea la adhesión a una pedagogía centrada en la "educación popular" y la "escuela activa". En el tramo final, la autora explica cómo se fue consolidando como figura intelectual entre sus contemporáneos, para lo cual apela al análisis de los homenajes que se le sustanciaron, a las redes intelectuales establecidas con Herminia Brumana y Juan Antonio Solari, junto a otras relaciones conformadas con editores y algunos colegas, como Sara del Carmen Ugazzi y Rodolfo Pérez Duprat, quienes también se convirtieron en sus biógrafos.

Flavia Fiorucci en el capítulo tercero indaga en las experiencias y representaciones de un sector de los maestros escasamente referenciados en los estudios de síntesis clásicos sobre la historia de la educación argentina, se trata de los maestros rurales que trabajaron en áreas de fronteras o en escuelas donde concurrían niños y niñas indígenas. A partir de los escritos autobiográficos de memorias y narraciones realizados por Jorge Abalos (1970), Julián Ripa (1980), Elsa Chaparro Aguirre (1990) y Demetrio Fernández (2013), la autora examina las condiciones que promovieron el contexto de producción de cada uno de los escritos e identifica marcas recurrentes en los cuatro textos, como el uso de ciertos tópicos, la apelación a representaciones y relatos de experiencias semejantes que ponían de manifiesto los alcances del mandato modernizador, nacionalizador y sanitarista que signaba la tarea docente. El "gesto autobiográfico" es interpelado en forma cautelosa y dialógica con las marcas de los diferentes itinerarios personales, la formación de los maestros, el recorrido profesional y las relaciones entabladas, no exentas de tensiones, con las comunidades y contextos socioeducativos en que esas experiencias estaban inscriptas. En ese sentido, el estudio muestra un cuadro elocuente que deja entrever una serie de representaciones compartidas y la impronta del mandato normalizador entre los maestros, aunque también visibiliza algunos planteamientos, a veces contradictorios con ese mandato, que dan cuenta de posicionamientos y valoraciones disímiles en referencia a las comunidades con las que les tocó interactuar.

En el capítulo Tizas y Apuntes: costumbres en común. Maestras, libros y prácticas de la enseñanza en la Argentina de 1930, Paula Caldo hace un contrapunto entre los recorridos biográficos de Herminia Brumana y Olga Cossettini, prestando especial atención a dos ensayos en las que ambas reflexionaron sobre sus experiencias pedagógicas como corolario de sus trayectorias profesionales. Articula la trama biográfica con el contexto de producción de los libros, las marcas de enunciación y algunas notas sobre la recepción de esos escritos. La investigadora se vale del análisis textual para explicitar el entramado de presencias de múltiples actores en la elaboración de esos saberes, agentes que se hacen visibles más allá de quien detente la autoría. El estudio es una invitación a pensar de manera rizomática y proteica estos y otros registros de la producción intelectual.

En la segunda parte del libro, Adrián Cammarota y Karina Ramacciotti exploran en las relaciones entre los saberes médicos vinculados al higienismo y la eugenesia 
educativa en el ámbito escolar durante la primera mitad del siglo XX. El primero de los estudios, en sintonía con otras investigaciones, parte del presupuesto de que las reformas estatales vinculadas con la medicalización de los escolares fueron impulsadas entre 1920-1940, aunque su aplicación en la práctica estuvo condicionada por una serie de factores. Con el objetivo de explicar avances y retrocesos del proceso de medicalización escolar, el texto sintetiza algunas de las limitaciones que tuvieron las propuestas de los médicos, Enrique Olivieri -en el Cuerpo Médico Escolar del Consejo Nacional de Educación- en relación a las colonias o escuelas para "niños débiles", y ciertas medidas adoptadas durante la gestión de Carlos Cometto en los servicios médicos escolares de la provincia de Buenos Aires, con especial atención al proceso que derivó en la implementación de la libreta sanitaria escolar y la ficha biotipológica escolar, aplicada en forma experimental en 1933, en dos escuelas bonaerenses.

En el capítulo Entrecruzamiento de los saberes técnicos y estatales. El caso de Telma Reca, el enfoque biográfico sirve como andamiaje para articular la producción académica de la médica argentina -en relación con la importancia de la escuela y la criminalidad, desde una mirada que cuestionaba las ideas hegemónicas del determinismo biológico- con el diseño de políticas sociales a través de su gestión en la Dirección de Maternidad e Infancia, tales como la organización de "escuelas especiales" para niños "anormales" o los jardines de infantes. A partir del diálogo entre el recorrido formativo, las redes de sociabilidad y las publicaciones de la médica, Ramacciotti analiza las intervenciones de Reca en las agencias estatales, atendiendo tanto a las condiciones sociales que marcaron el contexto de producción de esos saberes desde una perspectiva amplia que incluye el género, como a las formas de difusión y estrategias que incentivaron la puesta en práctica de cada una de las propuestas analizadas.

En el último capítulo, Expertos e intelectuales. Los arquitectos Manuel y Arturo Civit en el debate político y cultural en la década de 1930, Daniela Cattaneo propone el análisis de las producciones de esos profesionales y sus aportes específicos al programa de construcción de estatidad en Mendoza. A través de una selección de la producción de los Civit vinculada con la arquitectura escolar, la investigación muestra cómo esa planificación se convirtió en motivo de disputa política en esa provincia y los sentidos que cobraba la adopción de diversas perspectivas, tales como el racionalismo arquitectónico, el escolanovismo, el higienismo escolar. Además, el estudio deja entrever las posibilidades de una correlación con actores y propuestas de profesionales de otras jurisdicciones como Santa Fe y Córdoba, que resulta prometedora.

En síntesis, el libro expone las condiciones de posibilidad de emergencia de propuestas, representaciones y estrategias de un abanico de actores sociales que intervinieron en diferentes niveles y momentos de la educación argentina. En forma simultánea presenta un aporte en el orden de los procedimientos, al poner en la palestra formas alternativas del relato biográfico, en correspondencia con operaciones heurísticas que apelan a la utilización combinada de interpretaciones y registros diversos como autobiografías, homenajes, memorias, legajos, periódicos, epistolarios, publicaciones; instrumentos que permiten ampliar el horizonte de preguntas respecto del universo de agentes que actuaron en distintos tramos del sistema educativo. 